\title{
UNIVERSITY STUDENT PERCEPTIONS OF THE CURRENT AND FUTURE ROLE OF NON-CARBON EMITTING ENERGY SOURCES IN THE WORLD
}

\author{
ROBERT L. MAHLER ${ }^{1} \&$ MICHAEL E. BARBER ${ }^{2}$ \\ ${ }^{1}$ Department of Soil and Water Systems, University of Idaho, Moscow, Idaho, USA. \\ ${ }^{2}$ Department of Civil and Environmental Engineering, University of Utah, Salt Lake City, Utah, USA.
}

\begin{abstract}
This article documents university student perceptions of the role and viability of non-carbon emitting energy sources in the short term ( 1 to 3 years) and medium term (10 to 30 years) for Earth. Consequently, the perceptions of 7,980 students at the University of Idaho (Moscow, ID, USA) about the future of geothermal energy $(\mathrm{G})$, hydropower energy $(\mathrm{H})$, nuclear power $(\mathrm{NP})$, ocean thermal energy conversion (OTEC), solar energy (S) and wind energy (W) were measured between 1993 and 2016. All students were enrolled in the introductory environmental science class. Two survey instruments were used to gather this data. The first survey instrument evaluated six energy sources in 1994, 1998, 2002, 2006, 2010 and 2014. The second instrument focused on questions about nuclear energy. In the first survey a significant portion of the students considered solar, wind and nuclear power to be viable nonemitting carbon energy sources in the medium-term (10 to 30 years) future. Also, students taking the survey in later years $(2006,2010,2014)$ were much more likely to consider non-carbon energy sources viable in the near and mid-term than students taking the survey in 1994, 1998 and 2002. In general, $46.7 \%$ of students considered nuclear power a serious problem at the beginning of the course; however, at the end of the term less than $36 \%$ of students still held their initial negative opinion. In addition, a significant majority of the students changed from indicating that fossil fuels were preferable to nuclear energy, an opinion they held at the beginning of the course, to favoring or at least saying that nuclear power was no worse than fossil fuels at the conclusion of the term. The significant findings of this study were: (1) students considered both solar and wind energy viable alternatives that have the potential to be significant on a world-wide basis within 30 years; (2) students saw only a limited expansion of hydropower and geothermal energy in the next 30 years; and (3) once students were educated in an unbiased way - including both the pros and cons of using nuclear energy - they were more receptive to view the nuclear power option favorably.
\end{abstract}

Keywords: non-carbon energy sources, nuclear education, nuclear energy concerns, solar, student perceptions, wind.

\section{INTRODUCTION}

Many scientists believe that global climate change is the most important environmental issue that Earth faces. The threat of catastrophic climate change will require rapid decarbonization of the world's current energy systems making renewable energy sources an important part of the solution to this issue [1]. Compared to coal, oil and natural gas, nuclear power results in low carbon emissions and consequently may be important in the mitigation of the adverse effects of climate change [2]. China and the United States, the two largest sources of global carbon dioxide emissions, are currently promoting the use of nuclear power and other renewable sources including solar and wind power as a necessary response to limit global climate change [3]. Many agree that nuclear power is a viable option to control global greenhouse gas emissions; however, future development and utilization of the nuclear option will require both public acceptance and cooperation [4].

In addition to nuclear energy there are other several potential renewable energy resources that can be used to reduce carbon emissions on a global scale [5]. In 2013, renewable sources met $19.1 \%$ of the world's energy needs. This $19.1 \%$ was split between modern renewables $(10.1 \%)$ 
and traditional biomass (9\%) including wood, charcoal, straw from fields and animal dung. Many scientists discount traditional biomass because, although renewable, it may not be sustainable and it releases carbon dioxide into the atmosphere. Modern biomass and hydropower production account for $80 \%$ of this renewable, sustainable energy while wind, solar, tidal and geothermal energy account for the other $20 \%$ of modern renewable energy. Because modern biomass materials emit carbon dioxide they should also be removed from the list of non-carbon energy sources. Consequently, only about $6.5 \%$ of the world's current energy production is by non-carbon emitting, renewable, sustainable energy sources. Finally, nuclear power is a welldeveloped proven technology that can be expanded to increase its share of the total world energy; however, there are significant sustainability and social issues associated with it [6].

Although not considered renewable, nuclear energy does not emit significant amounts of carbon into the atmosphere. Consequently, when added to the non-carbon emitting, renewable, sustainable energy sources described above, approximately $9 \%$ of the current energy production used by humans does not emit carbon and consequently does not adversely impact climate change. To prevent significant climate change, the percentage of energy produced on this planet by the energy sources listed above must significantly increase by 2050 .

In the mid-1970s $20 \%$ of Americans opposed nuclear power and the opposition to nuclear power grew to almost $60 \%$ by the early 1980 s [7]. The change in attitude to nuclear energy is assumed to originate from enhanced understanding [8]. Consequently, after the TMI and Chernobyl accidents, activities for public acceptance were enhanced. Factors including good performance, energy/electricity supply concerns in the early 2000s, more outspoken support by leaders in government and industry and media attention to the nuclear renaissance has boosted public support for nuclear energy in the last decade [9]. By 2003, 64\% of the public in the United States favored the use of nuclear power - three times the support seen in the late 1970s. Communication with the public is a central factor in the acceptance of the future use of nuclear power to generate energy [10].

Current support for nuclear power is uneven. A recent study in the European Union showed relatively low support for nuclear power, even among the nations most concerned about climate change [11]. In the developed counties of Asia, public opinion is satisfied with the current share of power coming from nuclear energy and there is no strong sentiment to increase or decrease its share [2]. In contrast, support for nuclear power has been increasing in China and the United States [12]. Currently, 24 countries are considering building nuclear reactors.

The purpose of this article is twofold: (1) to evaluate the viability of renewable energy sources in the short term and medium term from a student perspective, and (2) to measure student opinions about the safety and future potential of nuclear energy in the world as affected by mores developed prior to entering college, mores developed in college and the effect of unbiased science presented using the principles of the scientific method in an introductory environmental science class over a relatively short 15 -week period.

\section{BACKGROUND}

Most students entering college in the United States bring with them a set of mores that have been strongly influenced by their parents and high school peers [13, 14]. Unfortunately, many of these beliefs are not strongly rooted in science. Consequently, it is important to expose students to an introductory environmental science class that is based on the principles of scientific methods rather than on the advocacy of stances on specific environmental issues.

Consequently, an introductory environmental science class was developed in 1993 at the University of Idaho. The purpose of this course was to teach students about environmental issues from a scientific basis rather than a basis of advocacy. In this way, students could base 
their responses and actions to issues on science rather than bias or simple beliefs. The 18 environmental issues covered in this course are: (1) population growth, (2) food resources, (3) ecology, (4) biodiversity, (5) non-renewable energy resources, (6) renewable energy resources, (7) nuclear energy, (8) water quantity, (9) surface water quality, (10) drinking water quality, (11) outdoor air pollution, (12) indoor air pollution, (13) acid rainfall, (14) ozone depletion, (15) global warming, (16) solid waste disposal, (17) sewage disposal and (18) hazardous waste.

After the energy units were covered in the course in the fall term 1994, 1998, 2002, 2006, 2010 and 2014, the students were asked to rate the viability of renewable energy sources and nuclear power in the short-term (1 to 3 years) and medium-term (10 to 30 years). The collected data is part of survey instrument I.

The teaching methodology of this course was evaluated in two different ways. First, at the end of each term enrolled students completed a course evaluation to indicate if they thought that there was any bias in the way issues were presented. The second instrument consisted of 32 statements about environmental issues, which students were asked to strongly agree, agree, disagree, strongly disagree or have no opinion about. This second instrument was given to students during the first day of class and again during the fifteenth week of the term so that student opinion change could be measured. This change in student opinion could be attributed to unbiased scientific education on environmental issues. This instrument (survey instrument II) allowed the instructor (senior author) and the Environmental Science Program at the University of Idaho to assess learning outcomes and to measure student opinions about environmental issues.

\section{METHODOLOGY}

Two major survey instruments were developed and used to measure university student perceptions of potential energy resources over time and are summarized in Table 1.

SURVEY INSTRUMENT I. The first survey instrument asked students to rate the following non-carbon emitting energy in terms of being part of the solution to climate change issues: geothermal $(\mathrm{G})$, hydropower $(\mathrm{H})$, nuclear power $(\mathrm{NP})$, ocean thermal energy conversion (OTEC), solar (S), and wind (W). Prior to taking the survey the students in the introductory environmental science class covered three units about energy. For each energy source students reacted to the following two statements: is a potential solution to both energy needs and climate change in the short-term (3 to 10 years)'

'_ is a potential solution to both energy needs and climate change in the medium term (10 to 30 years)'

Table 1: Summary of methods used in survey I and survey II.

\begin{tabular}{lllll}
\hline Purpose & Years conducted & $\begin{array}{l}\text { Students } \\
\text { participating }\end{array}$ & Timing & Statistics \\
\hline $\begin{array}{l}\text { SURVEY I } \\
\begin{array}{l}\text { Comparing renewable } \\
\text { sources }\end{array}\end{array}$ & $\begin{array}{l}\text { 1994, 1998, 2002 } \\
\text { 2006, 2010,2014 }\end{array}$ & 1,246 & $\begin{array}{l}\text { Mid-way through } \\
\text { term }\end{array}$ & $\begin{array}{l}\text { SAS t-tests } \\
\text { contrasts }\end{array}$ \\
$\begin{array}{l}\text { SUREY II } \\
\begin{array}{l}\text { Evaluating nuclear } \\
\text { energy }\end{array}\end{array}$ & $\begin{array}{l}\text { 1993-2016 } \\
(48 \text { terms })\end{array}$ & 7,980 & First week Last & SAS t-tests \\
\end{tabular}


For each of the 12 statements ( 6 energy sources x 2 terms) the students were instructed to circle one of the following choices: SA (strongly agree), A (agree), N (neutral or no opinion), $\mathrm{D}$ (disagree) or SD (strongly disagree). This survey instrument was conducted mid-way through the class right after the energy issues were covered. In addition to the survey answers students provided information about their major, gender and year in college. Students turned in the completed survey questionnaire on their way out of the classroom.

This survey instrument was conducted in the fall semesters 1994, 1998, 2002, 2006, 2010 and 2014. This survey was completed by 1,246 students - an average of 208 students each term.

The data from each completed survey were summarized and a statistical analysis was performed to measure opinion change. The collective 6 semester data sets were analyzed using the statistical analysis system (SAS) and, where appropriate, t-tests and orthogonal contrast comparisons were used to evaluate the interactions of gender, sampling year, student major and year in college [15].

SURVEY INSTRUMENT II. A survey instrument with 32 statements about specific environmental issues was developed in 1993. This instrument contained the following two statements specific to nuclear energy:

'Nuclear energy is a serious problem from an environmental standpoint'

'Nuclear energy is preferable to the use of fossil fuels'

For each of the 32 survey statements the students were instructed to circle one of the following answers: SA (strongly agree), A (agree), N (neutral or no opinion), D (disagree) or SD (strongly disagree). This survey instrument was included in the syllabus dossier that students received on the first day of class. In addition to the survey answers students provided information about their major, gender and year in college. Students turned in the completed survey questionnaire on their way out of the classroom. Students again received the same survey during the fifteenth week of the semester. Again, the completed survey instrument was collected at the end of the class period.

The same survey procedure was repeated for 48 straight semesters from fall 1993 through spring 2016. During this period of time 7,980 students completed the two surveys (start and end of semester). The average number of completed surveys was 173 per semester.

The data from each completed survey were summarized and a statistical analysis was performed to measure opinion change using the same procedure used for survey I.

\section{RESULTS AND DISCUSSION}

The two survey instruments discussed in this article were asked of students who took Environmental Science 101 between 1993 and 2016. This class has been taught every semester since the fall 1993 term. The first survey instrument was designed to ask students their perceptions of the future potential of energy sources that did not emit carbon and thus would minimize climate change. This instrument was administered in the fall terms of 1994, 1998, 2002, 2006, 2010 and 2014. A total of 1,246 students took this survey (average of 208 students per surveyed year).

The second survey instrument contained two questions on nuclear energy. These two questions discussed in this article were asked of students who took the introductory environmental science 101 class every semester from fall term 1993 through spring 2016. This class was taught every semester during this period for a total of 48 times. Enrollment ranged from a low of 27 in fall 1993, the first time this class was taught, to a peak of 367 in spring 2010. Students 
took this class for one of the three following reasons: (1) general interest, (2) requirement for their major, or (3) to fulfill the university science requirement required of all students. During this 24-year period 7,980 students answered the two survey questions contained in this article during the first and fifteenth weeks of the semester so that opinion change could be observed and evaluated.

\subsection{Short-term energy solutions}

Students were asked about the potential of non-carbon emitting energy sources in the shortterm future (1 to 3 years). The percentage of students that thought solar, wind, hydropower, geothermal, nuclear and OTEC had significant potential in the short term (1 to 3 years) in each survey year is shown in Table 2. In 1994, less than $20 \%$ of surveyed students thought that any of these energy sources were short-term solutions. Conversely, in 2014, over $20 \%$ of surveyed students thought that both solar (25\%) and wind energy (39\%) were viable shortterm solutions to reduce carbon output and stabilize climate change. This information is unique as similar studies on college student views of solar and wind energy in a controlled setting has not been published.

\subsection{Medium-term energy solutions}

Surveyed students were more optimistic about the potential of non-carbon emitting energy sources in the medium term (10 to 30 years). In 1994, solar (23\%), wind (16\%) and nuclear $(16 \%)$ were often cited as being potential solutions to carbon emissions in the medium term. By the 2014 survey, over half of the surveyed students thought that wind energy would serve as a solution for carbon emission and climate change. In addition, over a third of surveyed students considered solar (49\%) and nuclear (37\%) to be medium-term solutions.

It is interesting to note that over time the medium-term potential of energy sources increased based on student answers. This can be due to many things including increased familiarity with these modern energy sources outside of the college classroom and the observations that both solar and wind energy have greatly expanded since 1994. Students were also

Table 2: University of Idaho student agreement (strongly agree + agree) with each of the following energy sources as a potential solution to energy needs and limit climate change in the short term (1 to 3 years).

\begin{tabular}{lrrrrrr}
\hline & \multicolumn{6}{l}{ Survey year } \\
\cline { 2 - 6 } & \multicolumn{1}{l}{1994} & 1998 & 2002 & 2006 & 2010 & 2014 \\
\cline { 2 - 7 } Energy source & $\%$ & & & & & \\
\hline Solar & 10 & 13 & 13 & 18 & 18 & 25 \\
Wind & 8 & 10 & 12 & 20 & 26 & 39 \\
Hydropower & 6 & 6 & 3 & 8 & 4 & 6 \\
Geothermal & 5 & 6 & 8 & 8 & 7 & 8 \\
Nuclear & 12 & 14 & 15 & 17 & 21 & 20 \\
OTEC & 1 & 0 & 1 & 2 & 2 & 2 \\
\hline
\end{tabular}

$\mathrm{n}=1,246$ over entire study period 
able to recognize the limited potential for hydropower expansion. Interestingly, although not in commercial operation, almost one in five students thought that OTEC had enough potential to be significant 10 to 30 years into the future.

\subsection{Influence of time on energy solutions}

Student agreement on the potential of non-carbon-emitting energy sources for both the shortand medium-term changed between 1994 and 2014 (Table 3). Students were significantly more likely to see solar, wind and nuclear power as a potential energy solution in the short term in 2014 than they did in 1994 (Table 3). Even more importantly, students were more likely to see five out of the six energy sources as being important in the medium term when the differences between the 1994 and 2014 answers are considered. Only hydropower was not considered more viable by the 2014 survey takers compared to students who surveyed in 1994 for both the short- and medium-terms.

Based on the survey data it is obvious that students consider solar and wind energy to have a viable future. This is starting to prove out in the market place as the cost of wind energy is currently similar to the energy produced by coal. The cost of solar energy keeps falling and should be cost competitive to coal within 10 years. Although currently not on the radar of most people, college students see the potential of OTEC in the medium term. Although nuclear energy is more controversial, based on this survey instrument it has potential. Because of the controversy surrounding nuclear power and the fact that it is not currently considered a sustainable energy source (limited uranium supplies; waste disposal problems) a second survey instrument was used to delve further and investigate the potential and problems of nuclear power as seen by college students.

\subsection{Student demographics on energy solutions}

The demographics of gender, major and year in college influenced student answers. First, when compared to females, males were more likely to predict that nuclear power could play a significant role as a viable future energy source $(\mathrm{p}<0.03 *)$. Conversely, females were more

Table 3: Change in student agreement between 1994 and 2014 for each of the following noncarbon producing energy sources and to limit climate change in the short term ( 1 to 3 years) and medium term (10 to 30 years).

\begin{tabular}{lrrrrrr}
\hline Energy source & \multicolumn{2}{c}{ Short term } & \multicolumn{3}{c}{ Medium term } \\
\hline & 1994 & 2014 & Sign. & 1994 & 2014 & Sign. \\
\hline Solar & $10 \%$ & $25 \%$ & $* * * *$ & $23 \%$ & $49 \%$ & $* * *$ \\
Wind & $8 \%$ & $39 \%$ & $* * * *$ & $16 \%$ & $56 \%$ & $* * * *$ \\
Hydropower & $6 \%$ & $6 \%$ & NS & $5 \%$ & $6 \%$ & NS \\
Geothermal & $5 \%$ & $8 \%$ & NS & $7 \%$ & $15 \%$ & $*$ \\
Nuclear & $12 \%$ & $20 \%$ & $*$ & $16 \%$ & $37 \%$ & $* *$ \\
OTEC & $1 \%$ & $2 \%$ & NS & $2 \%$ & $18 \%$ & $* * *$ \\
\hline
\end{tabular}

Sign. $=$ significance $*=0.05 ; * *=0.01 ; * * *=0.001 ; * * * *=0.0001$.

$\mathrm{n}=1,246$ over the entire study period 
optimistic about the future roles of solar $(\mathrm{p}<0.04 *)$ and wind $(\mathrm{p}<0.002 * *)$ energy than males. Second, students in years three and four of college were more likely to envision wind, solar and OTEC as future energy solutions than their under class counterparts. Third, college major did influence the vision of the future of energy. Engineering, science and business majors viewed all non-carbon emitting energy sources more favorably than the student body in general. Conversely, social science, humanities and education majors viewed the future of nuclear power, hydropower and geothermal energy less favorably than the overall student population.

\subsection{Nuclear power as a problem}

The summary of student reactions to the statement 'Nuclear power is a serious problem from an environmental standpoint' are shown in Table 4. When averaged over the 24-year study, $48.1 \%$ of the students came into the class believing that nuclear power was a serious environmental problem. However, by the last week of the semester, lesser than $32 \%$ of the students felt that nuclear power was a serious problem. This change in attitude was statistically significant ( $\mathrm{p}=0.0001)$. Perhaps, even more insightful was the observation that the percentage of students disagreeing with the survey statement increased from $19.1 \%$ to $41.8 \%$. In addition, the percentage of students neutral to the survey statement also significantly declined by the end of the course $(\mathrm{p}=0.004)$.

Female college students were more likely to consider nuclear power a serious environmental problem than males both at the beginning and end of the environmental science class $(\mathrm{p}=0.0001)$. Females were $10.4 \%$ more likely to be pessimistic than males at the beginning of class and $7.9 \%$ more likely at the end of class to consider nuclear power a serious problem. As noted with the other factors discussed, education about nuclear power had a significant impact on student views.

Educational majors had a significant impact on the belief that nuclear power is a serious environmental problem (Table 5). The majors could be broken down into four general groupings. Students majoring in agriculture, business and engineering were the least likely to enter the course believing that nuclear power was a serious environmental problem $(36.0 \%$ to $40.1 \%$ ). Students majoring in science were the next group least likely to consider nuclear power as a serious environmental problem (44.2\%). About half of the students in the third group majoring in architecture, forestry and general studies had the preconceived notion that nuclear power was a serious problem $(48.5 \%$ to $51.1 \%)$. A majority of students majoring in education, humanities and social sciences came into this class believing that nuclear power is a serious problem (54.6\% to $60.1 \%$ ). Regardless of the majors by the end of the semester all major categories of students were much less likely to consider nuclear power as a serious environmental problem $(\mathrm{p}=0.0001)$.

Table 4: University of Idaho student reactions to the statement 'Nuclear power is a serious problem from an environmental standpoint'.

\begin{tabular}{lll}
\hline Response & Before (week 1), \% & After (week 15), \% \\
\hline Strongly agree/agree & 48.1 & 33.0 \\
Strongly disagree/disagree & 19.1 & 41.8 \\
Neutral & 35.6 & 25.2 \\
\hline
\end{tabular}

$\mathrm{n}=7,980 ; \mathrm{p}=0.00001$ 
Table 5: The influence of major on the University of Idaho students agreeing with the statement 'Nuclear power is a serious problem from an environmental standpoint'.

\begin{tabular}{lll}
\hline Major & Before (week 1), \% & After (week 15), \% \\
\hline Agriculture & 36.0 & 20.1 \\
Architecture & 48.5 & 30.3 \\
Business & 41.3 & 25.2 \\
Education & 60.1 & 50.4 \\
Engineering & 40.1 & 18.6 \\
Forestry & 49.4 & 32.1 \\
General Studies & 51.1 & 38.4 \\
Humanities & 54.6 & 44.3 \\
Science & 44.2 & 24.2 \\
Social Science & 56.5 & 46.2 \\
All respondents & 46.7 & 31.4 \\
\hline
\end{tabular}

$\mathrm{n}=7,980 ; \mathrm{p}=0.00001$

\subsection{Nuclear power is preferable to fossil fuels}

Young adults with little science background generally consider traditional fossil fuels safe and nuclear energy to be less safe. This observation has been confirmed 40 times (every semester) in the freshman environmental science class at the University of Idaho (Table 6). Approximately $30 \%$ of the 7,980 surveyed students thought that nuclear power was preferable to fossil fuels at the beginning of the term; however, this percentage almost doubled to $62.6 \%$ by the end of the term ( $\mathrm{p}=0.00001)$. There is little doubt that the relationship between carbon dioxide emissions and the burning of fossil fuels caused this opinion shift. It is interesting to note that student neutrality about this statement decreased from $52.6 \%$ to $18.3 \%$ by the end of the course.

Survey year affected student agreement regarding the statement 'Nuclear energy is preferable to the use of fossil fuels' (Table 7). In general, agreement at the beginning of the semester ranged from $33.6 \%$ to $35.3 \%$ between 1995 and 2016 but was statistically similar $(p=0.26)$. Conversely, agreement increased from 52.4\% in 1993-1994 to $74.2 \%$ in 2005-2009 at the end of the semester $(\mathrm{p}=0.0004)$. At the end of the semester, agreement between the 2005-2009 and 2010-2016 groups dropped from 74.2\% to 63.7\% (average of 2010-2012 and 2013-2016 groups), presumably due to the Fukushima accident ( $\mathrm{p}=0.0003)$.

Table 6: University of Idaho student reactions to the statement 'Nuclear energy is preferable to the use of fossil fuels'.

\begin{tabular}{lll}
\hline Response & Before (week 1), \% & After (week 15), \% \\
\hline Strongly agree/agree & 34.2 & 62.6 \\
Strongly disagree/disagree & 13.2 & 19.1 \\
Neutral & 52.6 & 18.3 \\
\hline
\end{tabular}

$\mathrm{n}=7,980 ; \mathrm{p}=0.00001$ 
Table 7: The influence of survey year on the University of Idaho students agreeing with the statement 'Nuclear energy is preferable to the use of fossil fuels'.

\begin{tabular}{lll}
\hline Survey years & Before (week 1), \% & After (week 15), \% \\
\hline $1993-1994$ & 28.6 & 52.4 \\
$1995-1999$ & 34.4 & 63.0 \\
$2000-2004$ & 35.3 & 66.8 \\
$2005-2009$ & 33.6 & 74.2 \\
$2010-2012$ & 35.2 & 64.1 \\
$2013-2016$ & 34.5 & 63.5 \\
All years & 34.6 & 63.4 \\
\hline
\end{tabular}

$\mathrm{n}=7,980 ; \mathrm{p}=0.00001$

Males were much more likely than females to favor nuclear power over fossil fuels at the beginning (43.1\% vs. $26.0 \%)$ and completion $(78.2 \%$ vs. $47.9 \%)$ of the environmental science course $(p=0.00001)$. The environmental science course increased the male rate of preference for nuclear power over fossil fuels by $35.1 \%$, while female preferences for nuclear power increased by only $21.9 \%$. This gender difference is wide and cannot be attributed to class size since over $53 \%$ of the 7,980 sampled students were female.

\section{CONCLUSIONS AND RECOMMENDATIONS}

University of Idaho students believe that energy sources that do not emit carbon dioxide and consequently minimize climatic impacts on Earth are currently available and will be practical, significant and implemented on a widespread basis over the next 10 to 30 years. College students have a high regard for both solar- and wind-based energy. College students appear to be in step with energy scientists that are trying to advance the use of solar and/or wind energy. Important findings from this study include:

- Back in 1994 only $23 \%$ of the student population felt that solar energy would be practical and widely installed within 10 to 30 years compared to $49 \%$ of students believing so in 2014.

- Wind energy potential is even more impressive from a college student standpoint as a majority of students surveyed in 2010 and 2014 believe this energy source will be widely used and important in the next 10 to 30 years.

- Over one-third of students think that nuclear power has the potential to be a more widespread energy source in the medium term.

- One in five students identified OTEC as a potential important energy source in the next 30 years despite the fact that the needed implementation technology is not yet developed.

- Hydropower and geothermal energy have little student interest as an answer to both future energy needs and protection of the Earth's climate.

- Most of the surveyed students entered college with negative perceptions of nuclear energy; however, the unbiased science education approach using the scientific method significantly changed student views.

- The current concern about global warming and consequent climate change resulting from greenhouse gas emissions through the use of coal, oil and natural gas makes nuclear energy a viable alternative that many college going adults in the United States are willing to accept. 
- In general, $46.7 \%$ of students considered nuclear power a serious problem at the beginning of the course; however, at the end of the term less than $32 \%$ of students still held their initial negative opinion.

- The most significant finding of this part of the study was that once students were educated about both the pros and cons of using nuclear energy they were more receptive to view the nuclear power option more favorably to stave off climate change.

\section{ACKNOWLEDGMENTS}

The authors would like to acknowledge the 7,980 undergraduate students at the University of Idaho who took part in this survey process.

\section{REFERENCES}

[1] Pidgeon, N. \& Demski, C.C., From nuclear to renewable: energy system transformation and public attitudes. Bulletin of the Atomic Scientists, 68, pp. 41-51, 2012. https://doi.org/10.1177/0096340212451592

[2] Liao, S., Tseng, W. \& Chen, C., Eliciting public preference for nuclear energy against the backdrop of global warming. Energy Policy, 38, pp. 7054-7069, 2010. https://doi.org/10.1016/j.enpol.2010.07.025

[3] Truelove, H.B. \& Greenberg, M., Who has become more open to nuclear power because of climate change? Climate Change, 116, pp. 389-409, 2013. https://doi.org/10.1007/s10584-012-0497-2

[4] Choi, Y.S., Kim, J.S. \& Lee, B.W., Public's perception and judgment on nuclear power. Annals of Nuclear Energy, 27, pp. 295-309, 2000. https://doi.org/10.1016/S0306-4549(99)00056-0

[5] REN21. Renewables 2015: global status report. Paris: REN21 Secretariet. ISBN 9783-9815934-6-4, 2013.

[6] Mahler, R.L. \& Barber, M.E., University student perceptions of the current and future role of nuclear energy in the world. WIT Transactions on Ecology and the Environment, 176, pp. 93-103, 2013.

https://doi.org/10.2495/ESUS130081

[7] Rosa, E.A. \& Dunlap, R.E., Nuclear power: three decades of public opinion. Public Opinion Quarterly, 58, pp. 295-324, 1994.

https://doi.org/10.1086/269425

[8] Ohnishi, T., Effect of nuclear education on public attitude. Journal of Nuclear Science and Technology, 32, pp. 1027-1038, 1995. https://doi.org/10.1080/18811248.1995.9731811

[9] Bisconti, A.S., Why Americans support nuclear energy - development and characteristics of public opinion in the US. ATW-Internationale Zeitschrift fur Kernenergie, 48, p. 456, 2003.

[10] Visschers, V.H.M., Keller, C. \& Siegrist, M., Climate change benefits and energy supply benefits as determinants of acceptance of nuclear power stations: investigating an explanatory model. Energy Policy, 39, pp. 3621-3629, 2011.

https://doi.org/10.1016/j.enpol.2011.03.064

[11] Pampel, F.C., Support for nuclear energy in the context of climate change: evidence from the European Union. Organization and Environment, 24, pp. 249-268, 2011. https://doi.org/10.1177/1086026611422261 
[12] Ahearne, J.F., Prospects for nuclear energy. Energy Economics, 33, pp. 572-580, 2011. https://doi.org/10.1016/j.eneco.2010.11.014

[13] Mahler, R.L., Shafii, B., Hollenhorst, S. \& Anderson, B.J., Public perceptions on the ideal balance between natural resource protection and use in the western USA. Journal of Extension, 46(1), 1RIB2, 2008.

[14] Mahler, R.L., Gamroth, M., Pearson, P., Sorensen, F., Barber, M.E. \& Simmons, R., Information sources, learning opportunities and priority water issues in the Pacific Northwest. Journal of Extension, 48(2), 2RIB2, 2010.

[15] SAS Institute Inc., SAS Online Document 9.1.3. Cary, North Carolina: SAS Institute Inc., 2004. 